\title{
AVALIAÇÃO IN VITRO DA AÇÃO ANTIFÚNGICA DO DIGLUCONATO DE CLORHEXIDINA E NISTATINA NO CONTROLE DO CRESCIMENTO DE Candida albicans
}

\section{IN VITRO EVALUATION OF ANTIFUNGAL ACTION OF CHLORHEXIDINA DIGLUCONATE AND NYSTATIN ON THE GROWING CONTROL OF Candida albicans}

\section{FARIAS, Nayanna Coutinho del; BUFFON, Marilene Magalhães ${ }^{2 *}$; CINI, Rafael ${ }^{3}$}

\author{
'Acadêmica da Graduação do Curso de Odontologia da UFPR \\ 2Professora do Departamento de Saúde Comunitária da UFPR, email: marilenebuffon@ufpr.br \\ ${ }^{3}$ Acadêmico da Graduação do Curso de Odontologia da UFPR \\ "Autor para correspondência: Rua Pref. Lothário Meissner 3400, 80210-170, Jardim Botânico, Curitiba-PR,
}

\section{RESUMO}

O estudo tem como objetivo avaliar comparativamente as propriedades antifúngicas da nistatina 100.000 Ul em relação à solução de digluconato de clorhexidina a $0.2 \%$. A suspensão de C. albicans foi semeada em meio de cultura de $\mathrm{BH}$ com ágar, com cerca de $6 \mathrm{~mm}$ de espessura distribuídos em placas de petri com escavações de $7 \mathrm{~mm}$ de diâmetro. Após 10 repetições, obteve-se os resultados de acordo com o halo de inibição formado pela solução. Para o digluconato de clorhexidina o halo de inibição foi de $27 \mathrm{~mm}$ e para nistatina foi $17 \mathrm{~mm}$. Assim, pode-se considerar a clorhexidina $0,2 \%$ no estudo in vitro como superior no combate antifúngico das cepas de leveduras em relação à nistatina.

Palavras-chaves: promoção de saúde, candidíase, microbiologia.

\section{ABSTRACT}

The study aim to compare the antifungal properties between 100.000 IU nystatin and $0.2 \%$ chlorhexidine digluconate solution. The C. albicans suspension was seeded in a BHI agar culture, with $6 \mathrm{~mm}$ of thickness distributed in Petri plates with $7 \mathrm{~mm}$ diameters holes. After 10 repetitions, the results were measured according to the inhibitions halos created by the solution. The chlorhexidine solution inhibition halo was $27 \mathrm{~mm}$ and the nystatin was $17 \mathrm{~mm}$. Therefore, the $0.2 \%$ chlorhexidine solution may be considered more effective them nystatin in the antifungal action against yeast strains.

Key words: health promotion, candidiasis, microbiology.

\section{INTRODUÇÃO}

As leveduras, especialmente a Candida albicans, são organismos comumente encontrados na cavidade oral de indivíduos saudáveis ou doentes. A região mais freqüentemente afetada é o dorso da língua, mas a C. albicans também pode ser encontrada na bochecha, gengiva, palato, bolsas periodontais e lesões refratárias. Essas regiões são consideradas importantes portas de entrada para infecções sistêmicas, portanto a prevenção da colonização oral por Candida merece grande atenção (ADDY, 1977).

Elas estabelecem um equilíbrio com o hospedeiro denominado simbiose, quando este equilíbrio é rompido devido a mudanças no mecanismo de defesa e no ambiente oral (quimio e radioterapia, HIV-positivo, etc), estas leveduras podem causar infecções orais oportunistas, que se não tratadas podem se tornar generalizada e/ou disseminarem sistemicamente provocando fungemia (GREENSPAN et al. 1994).

A candidíase orofaríngea apresenta como seu principal agente etiológico a C. albicans, comum em pacientes imunodeprimidos e normalmente é precedida de colonização das superfícies mucosas orais (THURMOND et al. 1991). A candídíase sistêmica, que está relacionada a altos índices de mortalidade, pode ocorrer devido à prévia colonização da cavidade oral ou da orofaringe, portanto a prevenção da colonização oral por Candida é de grande importância na prevenção de candidíase orofaríngea e sistêmica, principalmente em pacientes com neutropenia (BERKOWITZ et al. 1985).

Até hoje não existe uma terapia antifúngica ideal, ou os agentes empregados não são 
100\% eficazes ou apresentam efeitos indesejáveis pelos pacientes (†oxicidade, gosto ruim, etc). A nistatina, por exemplo, mostrou-se eficaz no controle das leveduras em estudos in vitro, no entanto em estudos in vivo essa eficácia não foi verificada devido a não aceitação pelos pacientes (náuseas e vômitos).

A nistatina é um antifúngico poliênico, relativamente insolúvel na água e instável. É usada no tratamento das infecções causadas por Candida da mucosa, pele e trato intestinal (YAGIELA, 1999). A nistatina tópica é a droga de escolha para o tratamento das infecções por Candida da cavidade oral. A nistatina pode causar leves e transitórios distúrbios gastrointestinais, como náuseas, vômitos e diarréia. A principal queixa associada à nistatina é seu gosto amargo, repugnante.

A clorhexidina é um detergente catiônico, uma Bis-biguanida não tóxica que é preparada sob a forma de diversos sais, entre eles o acetato, hidrocloride e o gluconato de clorhexidina (FLÖTRA, 1973). É considerada um antisséptico de amplo espectro que atua sobre bactérias gram positivas, gram negativas, fungos e leveduras (VINHOLIS et al., 1996). A clorhexidina apresenta grande afinidade às paredes celulares dos microrganismos, aos mucopolissacarídeos salivares e à hidroxiapatita (CAWSON et al., 1959; DENARDI, 1994). Seu uso na Odontologia possui efeito antiplaca maior que outros agentes antimicrobianos, devido à sua acentuada capacidade de adsorção aos dentes e às superfícies mucosas com posterior liberação na cavidade oral em níveis terapêuticos (BEIGHTON, 1991).

O estudo tem como objetivo avaliar comparativamente as propriedades antifúngicas da nistatina $100.000 \mathrm{UI}$, que é o antimicrobiano mais utilizado para o tratamento desta enfermidade, em relação à solução de digluconato de clorhexidina a 0.2\% (CHX).

\section{REVISÃO BIBLIOGRÁFICA}

Com o objetivo de reduzir as complicações orais durante a quimioterapia e o transplante de medula óssea, EPSTEIN et al. (1992) realizou um estudo em 86 pacientes portadores de leucemia tratada com quimioterapia ou transplante de medula óssea. Determinou o potencial dos enxágues de clorhexidina, nistatina, e solução salina na redução de infecções orais e subseqüente infecção sistêmica, de mucosite e de gengivite. Os pacientes foram divididos em 4 grupos de enxágüe: clorhexidina $0.2 \%$, nistatina a 100.000 Ul/ml, clorhexidina associada com nistatina, e solução salina.

EPSTEIN et al. (1992) observou que após intensa quimioterapia, 30\% dos pacientes apresentaram Candida na cavidade oral. Com o uso dos enxágues, a Candida foi identificada em 35\% dos pacientes que usaram clorhexidina, $21 \%$ dos que usaram clorhexidina associada a nistatina, 37\% dos que usaram nistatina, e 28\% dos que usaram solução salina. Culturas sanguíneas positivas para infecção foram vistas em $26 \%$ dos pacientes; destes, seis morreram com candidíase sistêmica devido à prévia colonização oral e orofaríngea. Os resultados deste estudo não demonstraram nenhum efeito profilático da nistatina na colonização oral por Candida, e demonstraram complicações do uso da nistatina, tais como gosto ruim, náuseas e vômitos. Com relação à clorhexidina, os pacientes tiveram uma boa aceitação do enxágüe, mas não houve redução significativa das ulcerações e das mucosites orais. Dessa forma, a combinação de agentes tópicos e sistêmicos, requer estudos futuros para determinar o protocolo mais efetivo na redução de colonização por Candida, na prevenção de candidíase orofaríngea e sistêmica e no controle de colonização e infecção fúngica. 
KULAK et al. (1994) comparou os efeitos do fluconazole, fluconazole em conjunto com clorhexidina, e confecção de novas dentaduras bem adaptadas no tratamento de estomatite generalizada por dentadura (EGD), que possui como principal agente etiológico a C. albicans. Logo após o término do tratamento os resultados indicaram que no primeiro grupo (fluconazole) houve cura da EGD em 40\% dos pacientes, e em 47\% houve melhorias; no segundo grupo (fluconazole associado com clorhexidina) houve cura da EGD em $54 \%$ dos casos, e em 33\% houve melhorias; no terceiro grupo (novas dentaduras) ocorreul $3 \%$ de cura e $20 \%$ de melhorias. Estes resultados mostram que a aplicação tópica de clorhexidina nas superfícies das dentaduras em associação com o fluconazole sistêmico pode ser uma alternativa viável para o tratamento de EGD, em comparação com o tratamento somente com fluconazole sistêmico.

Segudo CANDIDO et al. (1996), a clorhexidina é bem mais efetiva do que outros produtos, no que diz respeito à inibição de C.albicans. O estudo determinou a CIM do Cepacol, Malvona e Periogard, frente a 30 cepas de C.albicans. O Periogard (clorhexidina) inibiu 100\% das cepas a uma concentração de $6.4 \mu \mathrm{g} / \mathrm{ml}$ (DIM de 1:200), o Cepacol inibiu 100\% a uma concentração de $25.6 \mu \mathrm{g} / \mathrm{ml}$ (DIM de 1:20), a Malvona inibiu 96\% das cepas a uma concentração de $12.8 \mu \mathrm{g} / \mathrm{ml}$ e $100 \%$ de inibição só foi alcançada na concentração de $25.6 \mu \mathrm{g} / \mathrm{ml}$ (DIM de 1:200).

GIULIANA et al. (1997) através do estudo para investigar as propriedades antifúngicas in vitro de sete enxágues bucais contendo agentes antimicrobianos. Foram avaliados concentração fúngica mínima (CFM) e tempo de ação à metade da concentração comercial dos enxágües bucais, entre eles, Corsodyl (digluconato de clorhexidina 0,2\%), Dentosan (digluconato de clorhexidina 0,2\%) e Plak Out (digluconato de clorhexidina 0, $12 \%$ ). As espécies de Candida (incluindo C. albicans) foram isoladas da cavidade bucal de pacientes portadores de candidíase. As diferenças da concentração inicial de clorhexidina dos enxágues foram devidamente ajustados e os resultados indicaram que os enxágües bucais contendo agentes antimicrobianos podem representar uma alternativa apropriada, em relação às drogas antifúngicas convencionais, no combate à candidíase oral.

No estudo, GIULIANA et al. (1997) sugeriu que os enxágües com clorhexidina demonstraram eficácia frente à Candida albicans. Além disso, acrescentou que a efetividade de enxágues antimicrobianos como agentes antifúngicos precisa ser avaliada em futuros testes clínicos.

AZEVEDO et al. (1999) determinou a diluição inibitória máxima (DIM) através de estudo com Periogard e Própolis frente às cepas de leveduras isoladas de cavidades orais de pacientes com e sem lesões. Foram avaliados 50 indivíduos de ambos os sexos e faixa etária média de 42.5 anos, da Clínica de Semiologia da FORP - USP.

Na pesquisa, a espécie prevalente das amostras foi a C. albicans (48\% das amostras de saliva, 28\% em língua normal, 14.3\% em língua fissurada, e 67.8\% das amostras das lesões). O maior número de cepas inibidas foi alcançado com uma diluição de Própolis de 1:20 e com uma diluição de Periogard de 1:160. Com relação à C. albicans, a DIM variou de 1:100 a 1:160 para o Periogard, e 1:20 a 1:40 para o Própolis.

AZEVEDO et al. (1999) considera o fato de que os efeitos in vitro não podem ser diretamente comparados com efeitos in vivo, os resultados indicam que leveduras de diferentes espécies do gênero Candida puderam ser inibidas pela aplicação dos produtos comerciais Periogard e Própolis com propósito terapêutico e/ou preventivo contra candidíase oral. 
CHANDRA et al. (2001) representou um reservatório para micróbios orais em biofilmes de dentadura. O objetivo do estudo foi comparar a suscetibilidade antifúngica da C. albicans frente à clorhexidina e nistatina. Os resultados mostraram $50 \%$ de redução da atividade metabólica (RAM) de C.albicans desenvolvida em biofilmes à concentrações de $16 \mu \mathrm{g} / \mathrm{ml}$ para nistatina e $128 \mu \mathrm{g} / \mathrm{ml}$ para clorhexidina; e 50\% de RAM de C. albicans desenvolvida em meio de cultura à concentrações de $1.0 \mu \mathrm{g} / \mathrm{ml}$ para nistatina e $4.0 \mu \mathrm{g} / \mathrm{ml}$ para clorhexidina. Esses resultados sugerem que a C.albicans desenvolvida em associação nos biofilmes são bem mais resistentes à ação desses produtos do que a C. albicans desenvolvida isoladamente em meios de cultura.

\section{MATERIAL E MÉTODOS}

A atividade da solução de digluconato de clorhexidina (CHX) a 0,2\% e da solução de nistatina a 100.000Ul/ml foi testada sobre o cultivo de Candida albicans ATCC (Americam Type Culture Collection) 1031(Fig. 1).

Foi utilizado um meio de cultura de BHI com ágar, com cerca de $6 \mathrm{~mm}$ de espessura, distribuídos em placas de Petri de $10 \mathrm{~cm}$ de diâmetro, e sobre a superfície do meio foram feitas escavações de $7 \mathrm{~mm}$ de diâmetro. Nestas escavações foram colocadas as soluções na quantidade de $150 \mu \mathrm{l}$ por meio de uma pipeta automática.

A suspensão contendo C. albicans foi preparada, comparando-se a turbidez com o tubo no 5 da Escala de Mac Farland. Um swab de algodão não tóxico, esterilizado foi submerso no inóculo. Para eliminar o excesso de líquido o swab foi pressionado e girado contra as paredes do tubo. Em seguida foi realizada a semeadura das soluções de CHX e nistatina no meio de cultivo, com o cuidado de distribuir o inóculo de maneira uniforme. As placas foram incubadas de 24 a 48 horas à $37^{\circ} \mathrm{C}$, com um total de 10 repetições (Fig. 2).

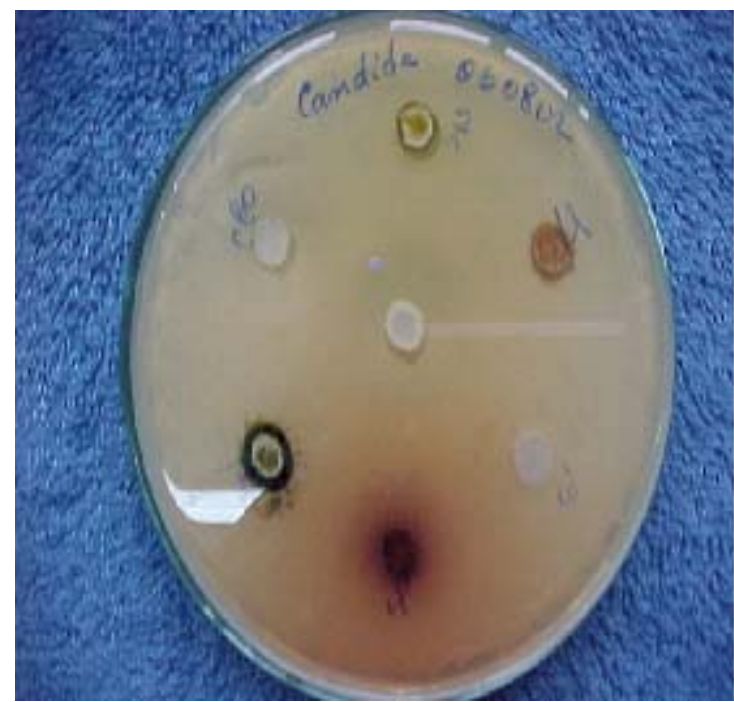

FIGURA 1-MEIO DE CULTURA CONTENDO A SUSPENSÃO DE C. albicans

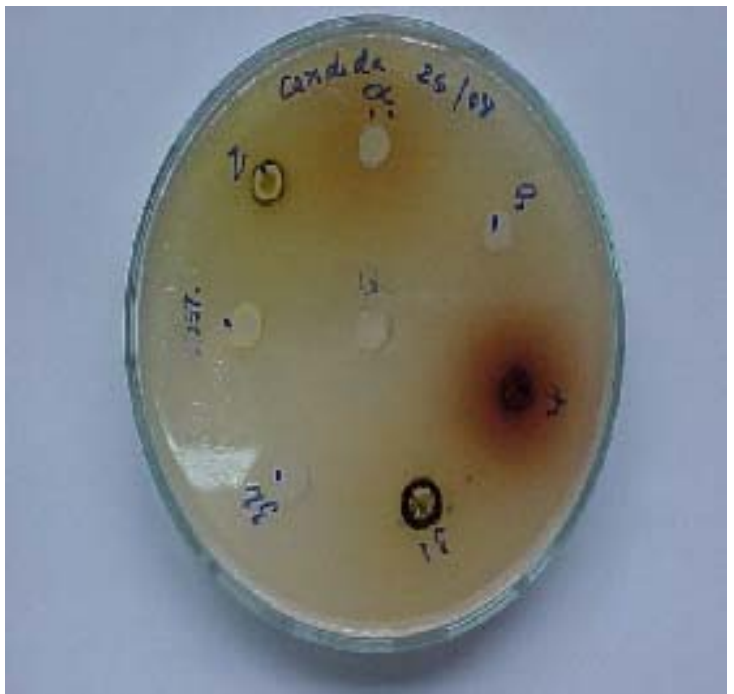

FIGURA 2- SEMEADURA DAS SOLUÇÕES DE CHX E NISTATINA

Após a incubação de 24 a 48 horas à $37^{\circ} \mathrm{C}$, observou-se a formação de halos de inibição em torno das escavações contendo solução de digluconato de clorhexidina a 0,2\% e nistatina a $100.000 \mathrm{Ul} / \mathrm{ml}$. Os diâmetros dos halos de inibição foram medidos com o auxilio de régua milimetrada e submetidos à análise. 


\section{RESULTADOS E DISCUSSÃO}

Os resultados obtidos nos testes in vitro através dos cálculos das medidas dos halos de inibição (Fig. 3) foram os seguintes: a solução de digluconato de clorhexidina a $0.2 \%$ apresentou halo de inibição de 27mm; e a solução de nistatina a $100.000 \mathrm{Ul} / \mathrm{ml}$ mostrou halo de inibição de $17 \mathrm{~mm}$ ( Tabela 1).

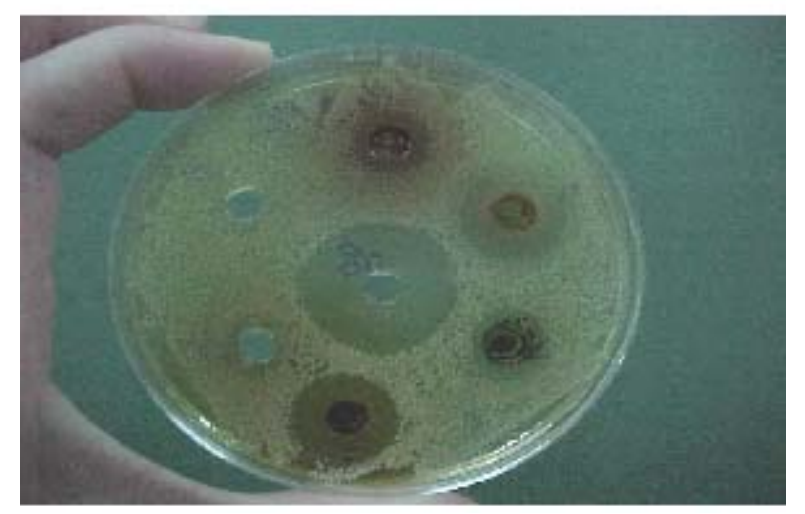

FIGURA 3- FORMAÇÃO DOS HALOS DE INIBIÇÃO, CHX NO CENTRO E NISTATINA AO REDOR

TABELA 1- RESULTADOS OBTIDOS

\begin{tabular}{cc}
\hline SOLUÇÃO & HALO \\
\hline Digluconato de clorhexidina 0,2\% & $27 \mathrm{~mm}$ \\
Nistatina $100.000 U \mathrm{I} / \mathrm{ml}$ & $17 \mathrm{~mm}$ \\
\hline
\end{tabular}

Dessa forma, a solução de clorhexidina demonstrou uma ação antifúngica frente às cepas de C. albicans superior à solução de nistatina (Fig. 4,5 ), confirmando os resultados obtidos pelos autores citados na revisão bibliográfica (GIULIANA et al. 1997; AZEVEDO et al. 1999; CANDIDO et al. 1996; CHANDRA et al. 2001; KULAK et al. 1994; EPSTEIN et al. 1992).

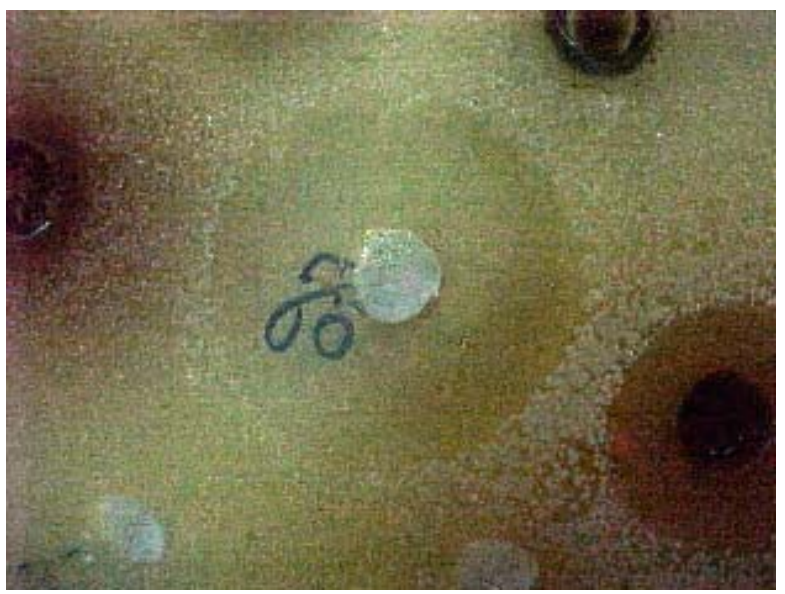

FIGURA 4 - HALO DE INIBIÇÃO DA CHX MAIOR EM RELAÇÃO À NISTATINA

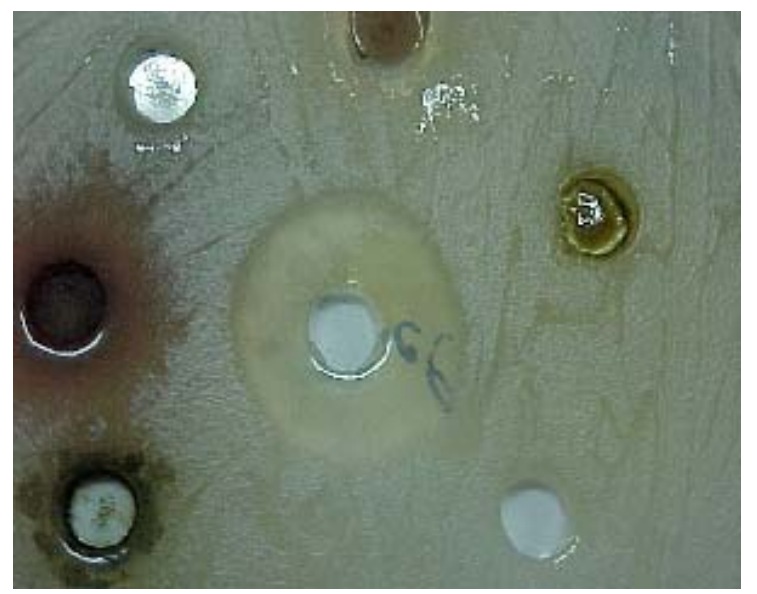

FIGURA 5 - AÇÃO ANTIFÚNGICA SUPERIOR DA CHX FRENTE AS CEPAS DE C. albicans 


\section{CONCLUSÃO}

O estudo in vitro sugere o uso de solução de digluconato de clorhexidina como substância terapêutica na prevenção, tratamento e alternativa complementar no combate antifúngico da candidíase oral. Uma vez que, leveduras da espécie C. albicans puderam ser inibidas pela aplicação de digluconato de clorhexidina (CHX) 0,2\%.

A continuidade da pesquisa será realizada para o estudo em futuros processos clínicos e determinação da concentração inibitória mínima (CIM).

\section{REFERÊNCIAS}

ADDY, M. Hibitane in the treatment of aphtous ulceration. J. Clin. Periodontol., v.4. p. 108-1 16.1977.

AZEVEDO et al. Candida sp in the Oral Cavity with and without lesions: Maximal Inhibitory Dilution of Propolis and Periogard. Revista de Microbiologia. p. 335- 340. 1999.

BEIGHTON, D. et al. Effects of chlorhexidine on proteolitic and glicosidic enzyme activities of dental plaque bacteria. J. Clin. Periodontol., 18:85/89,1991.

BERKOWITZ RJ, et al. Oropharyngeal Candida prophylaxis in pediatric bone marrow transplant patients. J. Pediatric hematol Oncol p.7:82-86, 1985.

CANDIDO et al. Determinação da concentração inbitória mínima de Cepacol, Malvona e Periogard, ante a Candida albicans isoladas da cavidade bucal. Revista de Odontologia UNESP. São Paulo, p.79-84, 1996.

CAWSON, R. A. \& CURSON, I. The effectiveness of some antiseptics on the oral mucous membrane. British Dent. J. v. 106, p.208-211, 1959.

CHANDRA et al. Antifungal Resistance of Candidal Biofilms Formed on Denture Acrylic in vitro. Journal of Dentistry Rest. p. 903-908. 2001.

DENARDI, B. B. O Uso da Clorexidina na Prática Odontológica. Revista da APCD. p. 1279- 1284. 1994.

EPSTEIN et al. Efficacy of chlorhexidine and nystatin rinses in prevention of oral complications in leukemia and bone marrow transplantation. Oral Surg Oral Med Oral Pathol. p.682- 688. 1992.

FLÖTRA, L. Different modes of chlorhexidine application and related local side effects. J. Periodont. Res.,v.18, supl.12, p.41-44.1973.

GREENSPAN et al. Treatment of oral candidiasis in HIV infection. Oral Surgery Oral Medicine Oral Pathology. p. 211 214. 1994

GIULIANA et al. In Vitro. Antifungal Properties of Mouthrinses Containing Antimicrobial Agents. Journal Periodontol. p.729-733.1997.

KULAK et al. Comparison of three different treatment methods for generalized denture stomatitis. The Journal of Prosthetic Dentistry. p.283-288. 1994.

THURMOND et al. Oral Candida albicans in bone marrow transplant patients given chlorhexidine rinses: Occurrence and susceptilities to the agent. Oral Surg Oral Med Oral Patho, v. 72. p. 291- 295. 1991.

VINHOLIS, A. H. Mecanismo de Ação da Clorexidina. Revista Periodontia. p. 281- 282. 1996.

YAGIELA, N. Farmacologia e Terapêutica para Dentistas. 3a ed.;São Paulo. p. 447-498. 1999. 